\title{
Mapping of Groundwater through the Integration of Remote Sensing and Vertical Electrical Sounding in ASALs: A Case Study of Turkana South Sub-County, Kenya
}

\author{
Daniel Mogaka Nyaberi ${ }^{*}$, Evans Basweti ${ }^{1}$, Justus Obiko Barongo² ${ }^{2}$, George Mokua Ogendi ${ }^{1}$, \\ Patrick Chege Kariuki ${ }^{3}$ \\ ${ }^{1}$ Department of Natural Resources and Environmental Science, Kisii University, Kisii, Kenya \\ ${ }^{2}$ Department of Geology, University of Nairobi, Nairobi, Kenya \\ ${ }^{3}$ Department of Geological Sciences, South Eastern Kenya University, Kitui, Kenya \\ Email: ebasweti@kisiiuniversity.ac.ke, mokua73@kisiiuniversity.ac.ke, justusbarongo@uonbi.ac.ke, pckariuki@seku.ac.ke, \\ *nyaberimogaka@gmail.com
}

How to cite this paper: Nyaberi, D. M., Basweti, E., Barongo, J. O., Ogendi, G. M., \& Kariuki, P. C. (2019). Mapping of Groundwater through the Integration of Remote Sensing and Vertical Electrical Sounding in ASALs: A Case Study of Turkana South Sub-County, Kenya. Journal of Geoscience and Environment Protection, 7, 229-243. https://doi.org/10.4236/gep.2019.711017

Received: October 13, 2019

Accepted: November 25, 2019

Published: November 28, 2019

Copyright $\odot 2019$ by author(s) and Scientific Research Publishing Inc. This work is licensed under the Creative Commons Attribution International License (CC BY 4.0).

http://creativecommons.org/licenses/by/4.0/ (c) (i) Open Access

\begin{abstract}
Turkana South Sub-County falls in the arid and semi-arid lands of Kenya, which are characterized temperatures of $20^{\circ} \mathrm{C}$ to $41^{\circ} \mathrm{C}$ with an average of $30.5^{\circ} \mathrm{C}$ and precipitation in the range of $52 \mathrm{~mm}$ to $480 \mathrm{~mm}$ per year. The area has limited availability of water resources. The area has a land surface of $18,000 \mathrm{~km}^{2}$ and lies between Longitudes $35^{\circ} 10^{\prime} 00^{\prime \prime}$ and $36^{\circ} 45^{\prime} 00^{\prime \prime}$ East and between Latitudes $1^{\circ} 0^{\prime} 00^{\prime \prime}$ and $3^{\circ} 0^{\prime} 00^{\prime \prime}$ North. The study area faces immense difficulties in trying to meet its water requirements for her rapidly increasing populace, livestock needs and other developmental programmes. Surface water in the area is becoming unobtainable, thus the choice of groundwater exploitation. Indeed with the snowballing demand necessitated by energy, agricultural and livestock production needs in this area, there is an appeal into investigation for groundwater in this greatly remote and extensive area. Thus, the success in the exploration, development and management of groundwater in such a large area calls for such methods that can easily be used to zero down to exploitable targets. Given the expansiveness of the study area, remote sensing (RS) has been used to map lineaments which in turn have been used to deduce faulting affecting the geology of the area. The mapping by RS helped in identifying weathered zones, the fracture systems and fault zones sign of deeper weathered zones which are interpreted to be potential areas since mainly water is stored within fractures and the weathered zones in subterranean and in hard rocks. In the field topographic expressions of faults and fractures which include; joints, fractures, scarps, river channels and slope
\end{abstract}


breaks were mapped and it was observed that there was a comparison of the features to the coincidence raster and aspect interpreted lineaments. The earmarked points were later investigated using vertical electrical sounding (VES) to establish their feasibility for groundwater availability and extraction. The investigated VES points in areas of high lineament density revealed decreasing resistivity with increasing depth of investigation, a confirmation of faulting. The data presented curves, type $\mathrm{KH}$, type KK, and type Q. Further investigation was done in points of low lineament density, considered to be least affected by faulting and deep weathering, which turned out to be having increasing resistivity with increasing depth of investigation, an indication of layered lithology. The zones of low lineament density are represented by a type A curve, a type $\mathrm{H}$ curve, type $\mathrm{HH}$. There is a good agreement in the results of remote sensing data and VES data models generated where the high lineaments density points concur with areas of good groundwater potential.

\section{Keywords}

Groundwater, Assessment, Remote Sensing, Lineaments, VES

\section{Introduction}

\subsection{Background of the Project}

As a factor of growth and development, water is a subject of great standing in many arid and semi-arid lands (Kamal \& Hamid, 2011). Turkana South SubCounty falls in the arid and semi-arid lands which are characteristic of limited availability of water resources. The Sub-County covers a land surface of 18,000 $\mathrm{km}^{2}$ and lies $35^{\circ} 10^{\prime}-36^{\circ} 45^{\prime}$ East Longitude and $1^{\circ} 0^{\prime}-3^{\circ} 0^{\prime}$ North Latitude. The Sub-County is located within Turkana County which is towards the northwestern part of Kenya (Figure 1), neighbored by the country of Uganda in the west, Lake Turkana to the east, West Pokot County in the south, Baringo County in the south eastern and Samburu County in the south-south east. The Sub-County characteristically is defined by warm and hot climate (Sultan, 1970). Recent study by Opiyo (2014) show that extreme drought scenarios in Turkana have gone up over the last 63 years, with 28.5 percent occurring between 1950 and 1970, up to 47.9 percent in the last two decades from 1990 to 2012. Indeed a report on Turkana county gives a general view of temperatures of $20^{\circ} \mathrm{C}$ to $41^{\circ} \mathrm{C}$ with an average of $30.5^{\circ} \mathrm{C}$ (Government of Kenya, 2013). The region has two rainfall seasons, where in the months of April to July experiences the long rains (akiporo) and the months of October to November happens the short rains in the range of $52 \mathrm{~mm}$ to $480 \mathrm{~mm}$ per year and an average of $200 \mathrm{~mm}$ (Turkana County Government Report, 2015).

The main drainage in the Sub-County is controlled by Kerio and the Suguta Rivers with their tributaries (e.g. Kalabata, Kasamanang and Nasaken) which Sultan (1970) notes that these are sandy rivers that contain water at depth and 


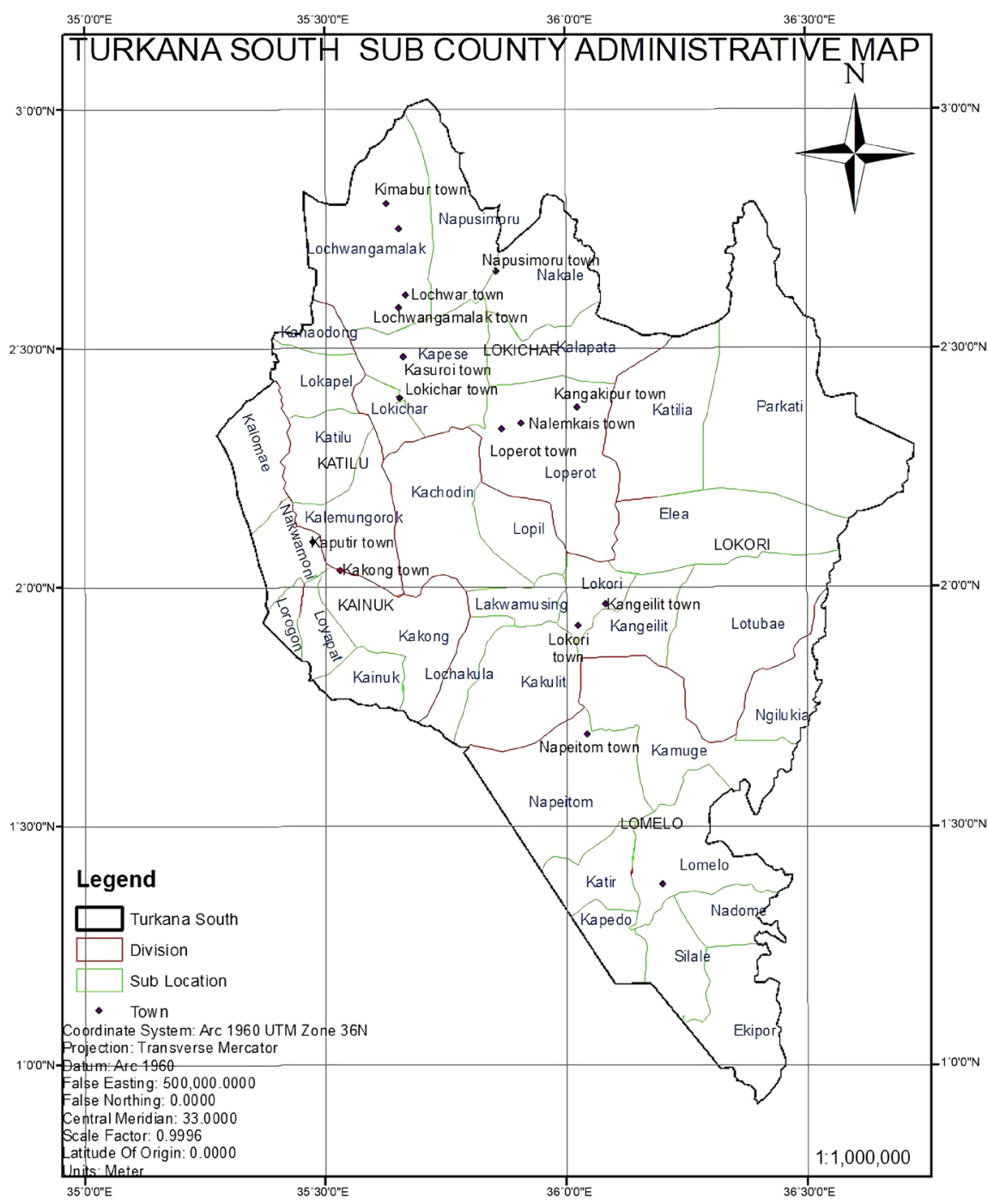

Figure 1. Location of Turkana South Sub-County within Turkana County in Kenya.

these supplies are of considerable importance in this arid region. Groundwater forms one important source of water in the Sub-County through boreholes and shallow wells although the outcome of sited and drilled boreholes is that 50 percent ends up dry. Groundwater drilling is very expensive and thus its exploration calls for the putting into practice of actual approaches of precision and that saves both money and time (Jawad \& Yahya, 2013). Therefore, without proper survey the results are uneven supply of water and uneconomical programmes of water provision through boreholes of which most turnouts dry upon drilling.

Jawad and Yahya (2013) notes the usability of applying remotely sensed data for establishing the most favourable locations of underground water, thus providing the best initial approach of pinpointing sites which can be pursued later by other ground methods.

Most boreholes and shallow wells in the study area are drilled proximate to rivers and stream channels, a demonstration that surface hydrology acts as a guide to most groundwater surveys rather than the pursuit of hydrogeology and 
hydrogeophysics. The siting of boreholes by means of the geophysical methods only occasionally is limiting and therefore the success of the procedure calls for incorporation of several relevant survey techniques. Indeed digital elevation models (DEMs) and geological maps have been used by Mogaji, Aboyeji \& Omosuyi (2011), to accomplish mapping and analysis of lineaments in the Basement Complex area of Ondo State, Nigeria. GIS's application of digital elevation model helps to improve the interpretation (Maina \& Tudunwada, 2017) of lineaments in analysis of remote sensing data. In the research the application of a GIS framework by overlaying the satellite imagery with the digital elevation maps helped in the demarcation of the tile lines that eventually resulted in mapping of the lineaments.

The use of remote sensing based data (Surajit, 2014) founded on spatial layers of groundwater controlling parameters through application GIS have been effective in coming up with the groundwater potential zone maps. Surajit (2014) further remarks that remote sensed data does not stand in place of the in situ information gathering, but rather it helps to minimize the measure of field information accumulation by other techniques for it is proven to assist in targeted measurements, therefore it is still vital to affirm the correctness of remotely sensed information and unquestionably remote sensing collaboration with other techniques. Remote sensing methods have played an unlimited role in groundwater searching in hard rock areas especially on lineament identification (Anbazhagan \& Manivel, 2010) and have been applied successfully to delineate areas with groundwater occurrences.

In this study, an endeavour was made towards the delineation and classification of probable underground water potential areas by using an integration of remote sensing and VES data. The correlation of faulting to changes in the course of the rivers (Mason \& Gibson, 1957), common feature of faulting as evident with the presence of Trellis drainage (Fairburn \& Matheson, 1970) and their association to groundwater is on large scale investigated. The research maps the groundwater potential of the Sub-County whose outcome will eventually act as a guide to siting productive boreholes and shallow wells contrary to the prevailing situation. The current approach for mapping used is able to assist in prioritizing potential regions thus offering backing for site-specific field geophysical examinations towards borehole siting.

\subsection{Hydrogeologic Background of the Study Area}

The Sub-County is an arid and semi-arid land and thus availability and access to water remains the biggest problem facing the people of Sub-County. The key water sources supplying the rural parts in Sub-County presently are unprotected hand dug wells, streams and boreholes. The hydrogeological situation of the region is rather difficult, with the geology of this part of the world being predominantly basement metamorphic rocks and igneous rocks, all of which naturally forms poor aquifers. The account of the geology of the area is given as Miocene basalts (Dodson, 1963) nephelinites (Champion, 1935) and amphibolites and the 
gneisses (McCall, 1964). The existence of volcanic rocks' source is taunted to be from a number of central rift volcanoes (Sultan, 1970). Gwynne (1969) has given an account of the occurrence of recent sedimentation in river channels which are associated with groundwater potential.

Equally, fracture and fault zones offer the best areas for groundwater movement, recharge and storage. Equally some areas are covered by sedimentary rocks both consolidated and unconsolidated including clastic sediments, limestone and other carbonate rocks.

\section{Materials and Methods of Research}

\subsection{Remote Sensing}

Remote sensing denotes, the attaining of info concerning things or spaces on the Earth's surface deprived of the direct contact with the object or area, where many sensing devices record information related to an object by measuring reflection and radiation of electromagnetic energy transmitted from the object's surfaces (Shefali, 2013). The data used is from sentinel 1 (Zakaria et al., 2017), is more effective in restitution of lineaments as compared to Landsat-8 and ASTER. The sentinel 1's operation is in four exclusive acquisition modes: 1) StripMap (SM), 2) Interferometric Wide swath (IW), 3) Extra-Wide swath (EW) and 4) Wave (WV). The one of interest is the operation in single polarization ( $\mathrm{HH}$ or $\mathrm{VV})$ and dual polarization $(\mathrm{HH}+\mathrm{HV}$ or $\mathrm{VV}+\mathrm{VH})$. This is normally executed by one transmit cable (switchable to $\mathrm{H}$ or $\mathrm{V}$ ) and two parallel receive cables for $\mathrm{H}$ and $\mathrm{V}$ polarization and on synthesis generated lineaments which are key in analysis of the terrain. The secondary data from the primary conflict-free mode over land, IW was used. Sentinel-1 Wave mode is similar to ERS and Evnisat wave mode imaging but with improved spatial resolution, larger vignettes and a "leap frog" acquisition pattern.

The sentinel series observes the earth at high resolution and therefore is very useful in groundwater management and other applications and information services. In this research, the assembly of a false-colour composite image (Sentinel 1a cross-polarised $(\mathrm{VH})$ ) image for the study area by combination of selected spectral band ratios and maps was used to develop Sentinel 1a VV Polarised image. The decision to use $\mathrm{VH}$, is that they show a good contrast and enough detail permit hydrographic network mapping where minimum vegetation is available (Saint-Jean \& Singhroy, 2000), whereas the VV polarization permits a better positioning of alignments in form of faults, scarps, banks and therefore vital in mapping roughness variations.

\subsection{Vertical Electrical Sounding Method}

The VES method was achieved by deployment of the Schlumberger configuration in data collection. The Abem Terrameter LS resistivity meter equipment was used in VES data collection. In the Schlumberger array four electrodes; A and $\mathrm{B}$ (current electrodes), and $\mathrm{M}$ and $\mathrm{N}$ (potential electrodes) are used in 
probing the subsurface (Figure 2).

The theoretical assumption is that the medium penetrated by the current in the sub-surface of the earth is being homogeneous and isotropic and thus the resistivity $\mathrm{p}$, and the potentials $\mathrm{V} \mathrm{M}$ and $\mathrm{V} \mathrm{N}$ measure happening at $\mathrm{M}$ and $\mathrm{N}$, respectively. The total current I flows away from or toward each electrode across the surface of a half sphere with area $\frac{1}{2}\left(4 \pi r^{2}\right)$ and with the distances between the electrodes given by $r_{11}, r_{12}$, etc., and $V=0$ infinitely far from the current source, the potentials at $\mathrm{M}$ and $\mathrm{N}$ are given by (Rhett, 2001):

$$
\begin{aligned}
& \nu \mathrm{M}=\frac{\rho I}{2 \pi}\left[\frac{1}{r_{11}}-\frac{1}{r_{21}}\right] \\
& v \mathrm{~N}=\frac{\rho I}{2 \pi}\left[\frac{1}{r_{12}}-\frac{1}{r_{22}}\right]
\end{aligned}
$$

Combination of the two equations gives a complete resultant in field measurement where the outcome equation is given as:

$$
\Delta v=v_{1}-v_{2}=\frac{\rho I}{2 \pi}\left[\frac{1}{r_{11}}+\frac{1}{r_{22}}-\frac{1}{r_{21}}-\frac{1}{r_{12}}\right]
$$

subsequently, the resistivity of the homogeneous subsurface is resolved by:

$$
\rho=2 \pi \frac{\Delta v}{I} k
$$

and where $K$ is referred to as the geometric factor as applied to the Schlumberger configuration and is given from the relationship:

$$
\frac{1}{k}=\frac{1}{r_{11}}+\frac{1}{r_{22}}-\frac{1}{r_{21}}-\frac{1}{r_{12}}
$$

otherwise normally, the geology is heterogeneous thus its resistivity is presented as apparent resistivity:

$$
\rho a=2 \pi \frac{\Delta v}{I} k
$$

and in cases where $r_{11}, r_{12}, r_{21}, r_{22}$ values are given in metres, and $\Delta v$ and $I$ are measured in millivolts and milliamperes respectively, then the pa would be in ohm-meters.

The VES data was collected in points of interest in the study area pursuant to

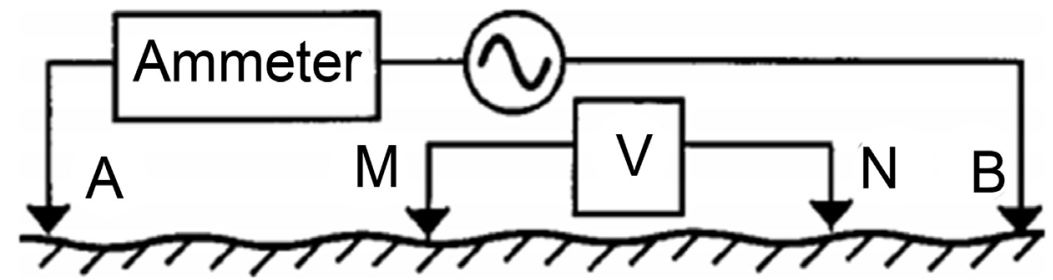

Figure 2. General configuration of the four surface electrodes in linear resistivity surveys. Current is delivered through the electrodes $\mathrm{A}$ and $\mathrm{B}$, and voltage readings are made through $\mathrm{M}$ and $\mathrm{N}$ (after Rhett, 2001). 
lineament interpretation made from remote sensing data. The VES was carried out in two different scenarios with four points done on areas of high-density lineaments (possible fault zones) and the rest on areas showing low density of lineaments (Figure 3). The points done on fault zone are $\mathrm{AA}, \mathrm{AC}, \mathrm{AD}$ and $\mathrm{AH}$, and the ones done on areas of low lineament density covers points $\mathrm{AB}, \mathrm{AE}, \mathrm{AF}$, AG and AI with their coordinates presented in Table 1.

\section{Results}

The remote sensing data was processed into giving drainage lines and lineaments extraction. Lineaments were extracted automatically by considering two fundamental calculations: foremost, was the usage of a filter in the detection of

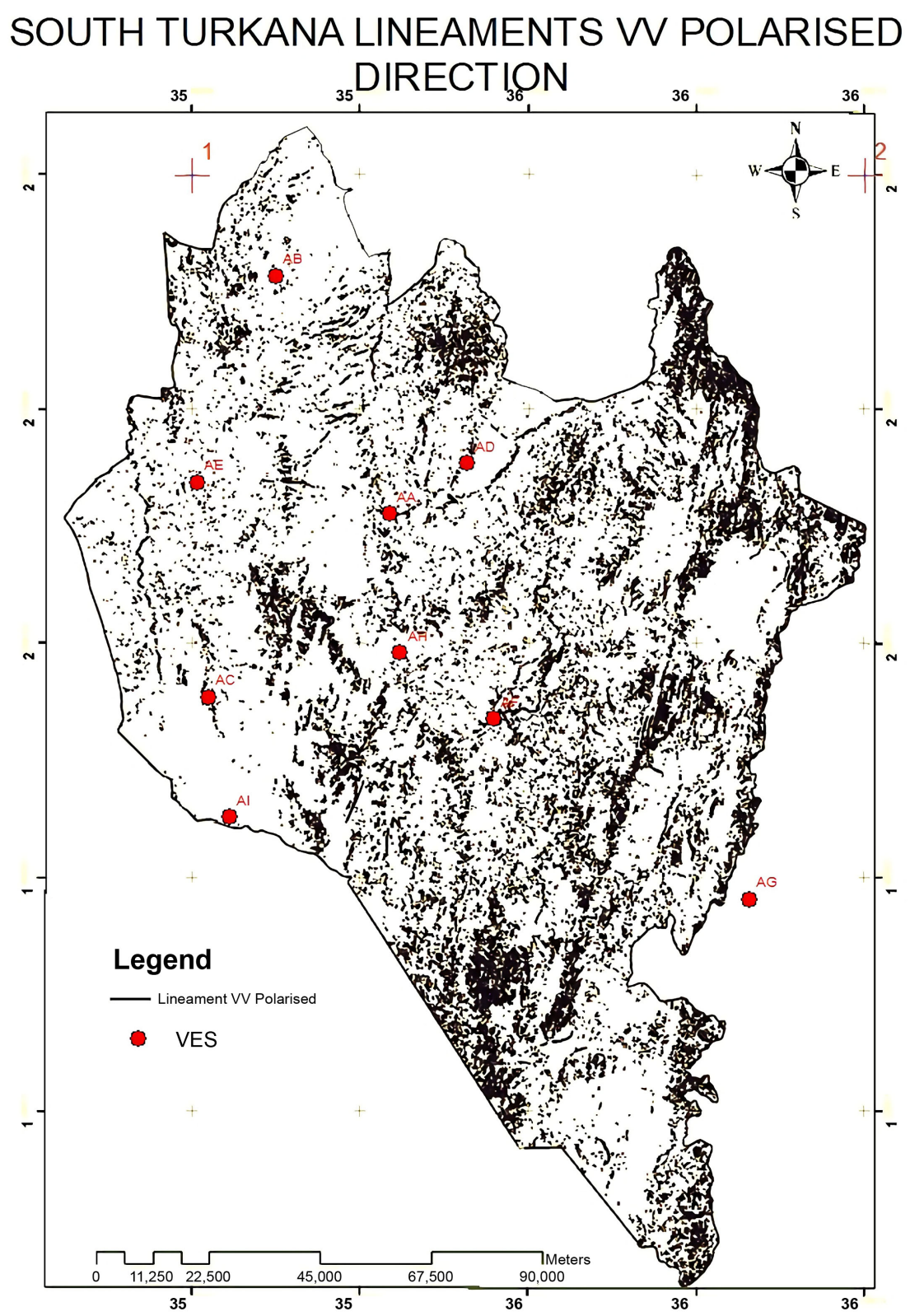

Figure 3. Vertical Electrical Sounding points overlaid on lineament VV polarized map. 
edges (contours) and secondly the detection of lines. The VH polarised map outlay show an impression of light toned and black toned regions of the study region (Figure 4).

Table 1. Points of interest where Vertical Electrical Sounding data was collected.

\begin{tabular}{cccc}
\hline ID & Latitude & Longitude & Area \\
\hline AA & $2^{\circ} 19^{\prime} 28.77^{\prime \prime} \mathrm{N}$ & $35^{\circ} 51^{\prime} 25.08^{\prime \prime} \mathrm{E}$ & Kalapata \\
$\mathrm{AB}$ & $2^{\circ} 45^{\prime} 20.58^{\prime \prime} \mathrm{N}$ & $35^{\circ} 39^{\prime} 0.54^{\prime \prime} \mathrm{E}$ & Locheremoit \\
$\mathrm{AC}$ & $1^{\circ} 59^{\prime} 28.65^{\prime \prime} \mathrm{N}$ & $35^{\circ} 31^{\prime} 40.02^{\prime \prime} \mathrm{E}$ & Kakong \\
$\mathrm{AD}$ & $2^{\circ} 24^{\prime} 54.76^{\prime \prime} \mathrm{N}$ & $35^{\circ} 59^{\prime} 55.25^{\prime \prime} \mathrm{E}$ & Akruchanait \\
$\mathrm{AE}$ & $2^{\circ} 22^{\prime} 52.3^{\prime \prime} \mathrm{N}$ & $35^{\circ} 37^{\prime} 27.9 " \mathrm{E}$ & Achukule-Lokichar Township \\
$\mathrm{AF}$ & $1^{\circ} 57^{\prime} 07.09^{\prime \prime} \mathrm{N}$ & $36^{\circ} 02^{\prime} 44.02^{\prime \prime} \mathrm{E}$ & Morulem \\
$\mathrm{AG}$ & $1^{\circ} 37^{\prime} 24.26^{\prime \prime} \mathrm{N}$ & $36^{\circ} 14^{\prime} 33^{\prime \prime} \mathrm{E}$ & Lotubae \\
$\mathrm{AH}$ & $2^{\circ} 04^{\prime} 18.8^{\prime \prime} \mathrm{N}$ & $35^{\circ} 52^{\prime} 36.4^{\prime \prime} \mathrm{E}$ & Lopii \\
$\mathrm{AI}$ & $1^{\circ} 46^{\prime} 21.58^{\prime \prime} \mathrm{N}$ & $35^{\circ} 33^{\prime} 59.58^{\prime \prime} \mathrm{E}$ & Kainuki 1 \\
\hline
\end{tabular}

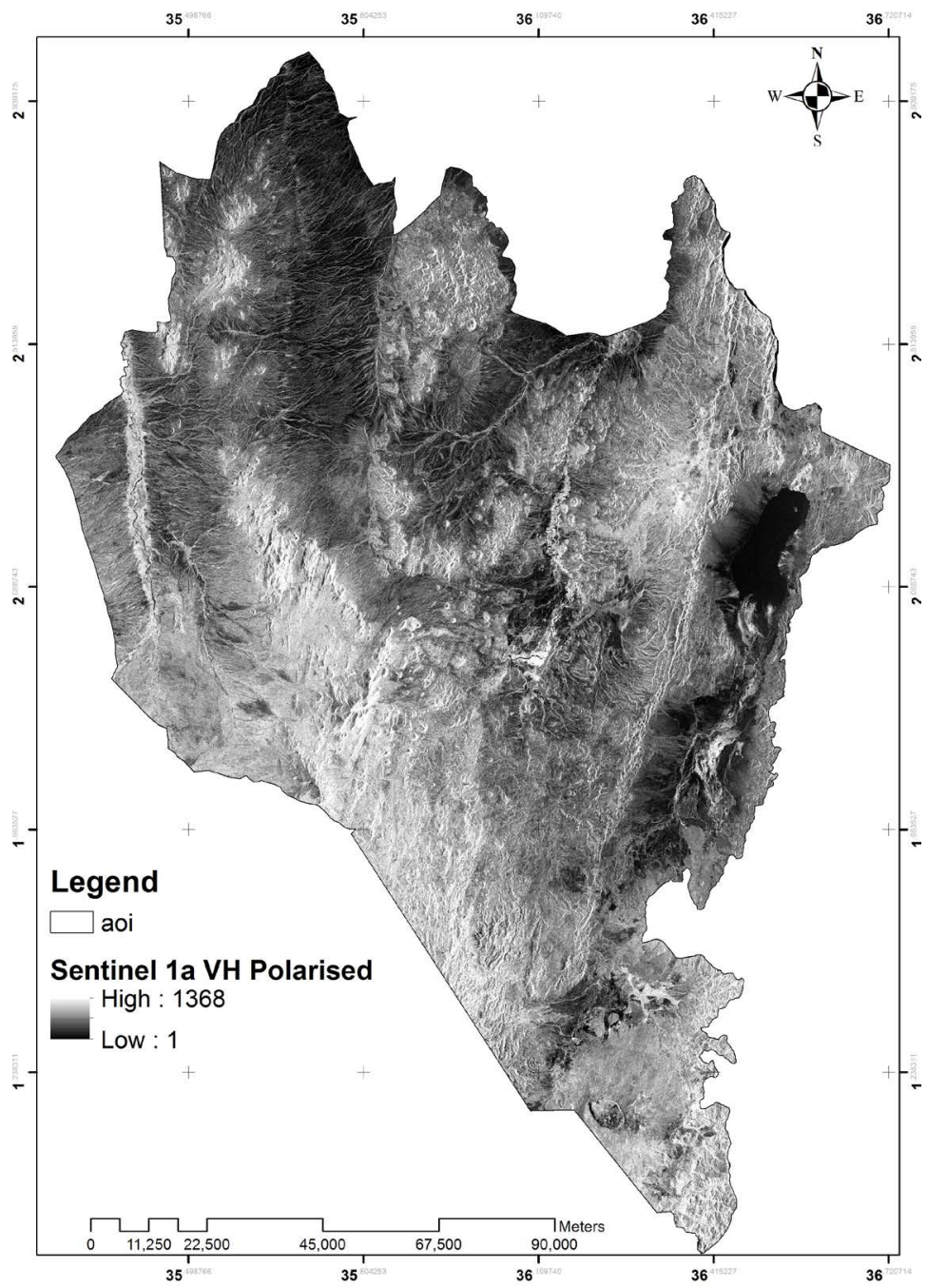

Figure 4. Showing Sentinel 1a VH Polarized map of the study area showing light toned and dark toned regions. 
The drainage lines are shown as light tones which have been analysed to give lineaments represented as green lines (Figure 5) of which on the ground represents weathering valleys revealed by grass covered flat bottoms and as an effect of sand deposits along river channels whereas dark toned regions are evident too because of vegetation. The VH images have a strong backscattering effect in regard to regions with vegetation thus greatly helps in uncovering probable of drainage network.

The analyzed data presented in Figure 6 and Figure 7 paints a picture of two separate scenarios in the areas investigated. The profiles in Figure 6 are VES results of points of low-density lineaments while the profiles in Figure 7 are VES results of points of high-density lineament.

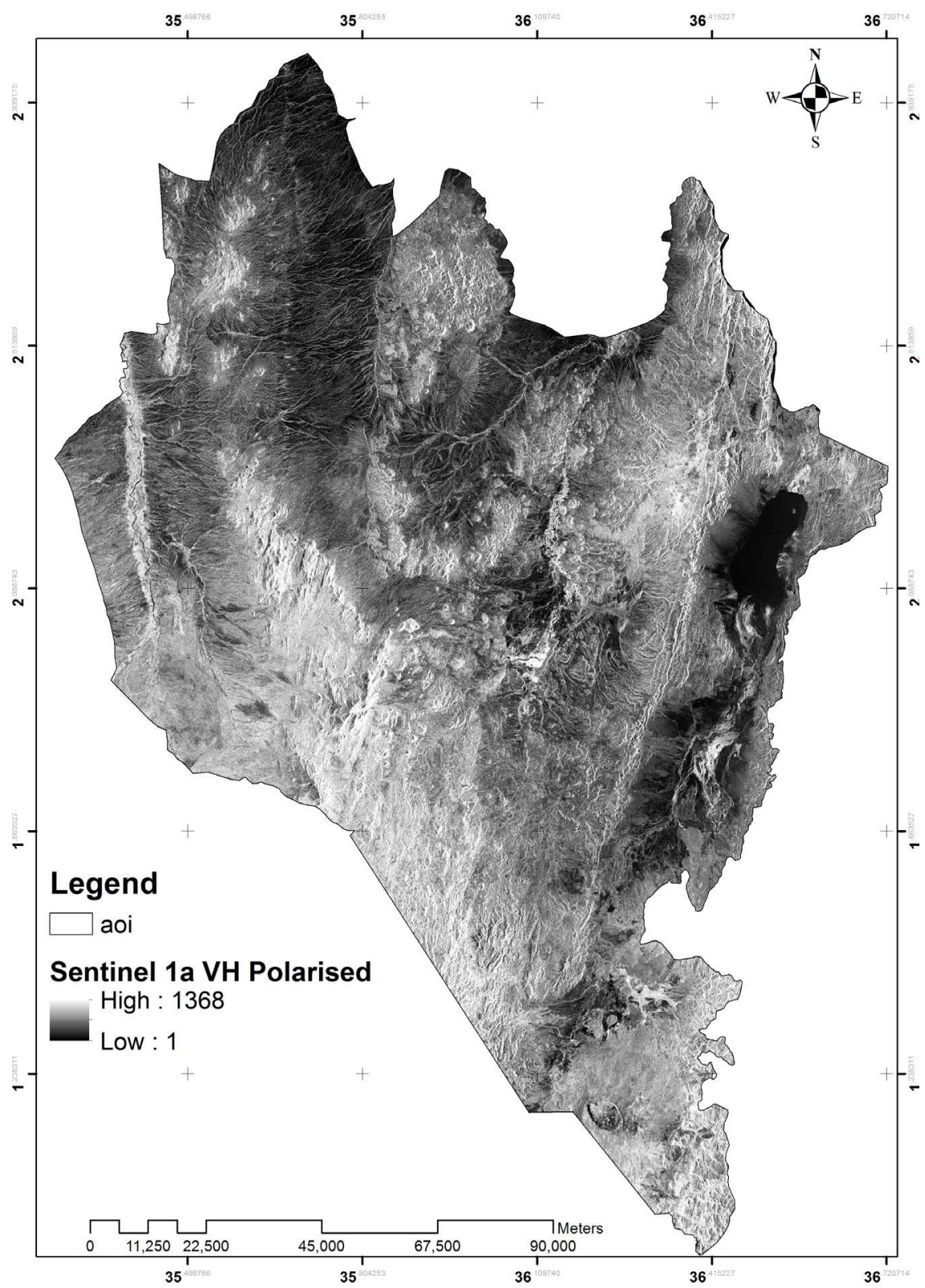

(a) 


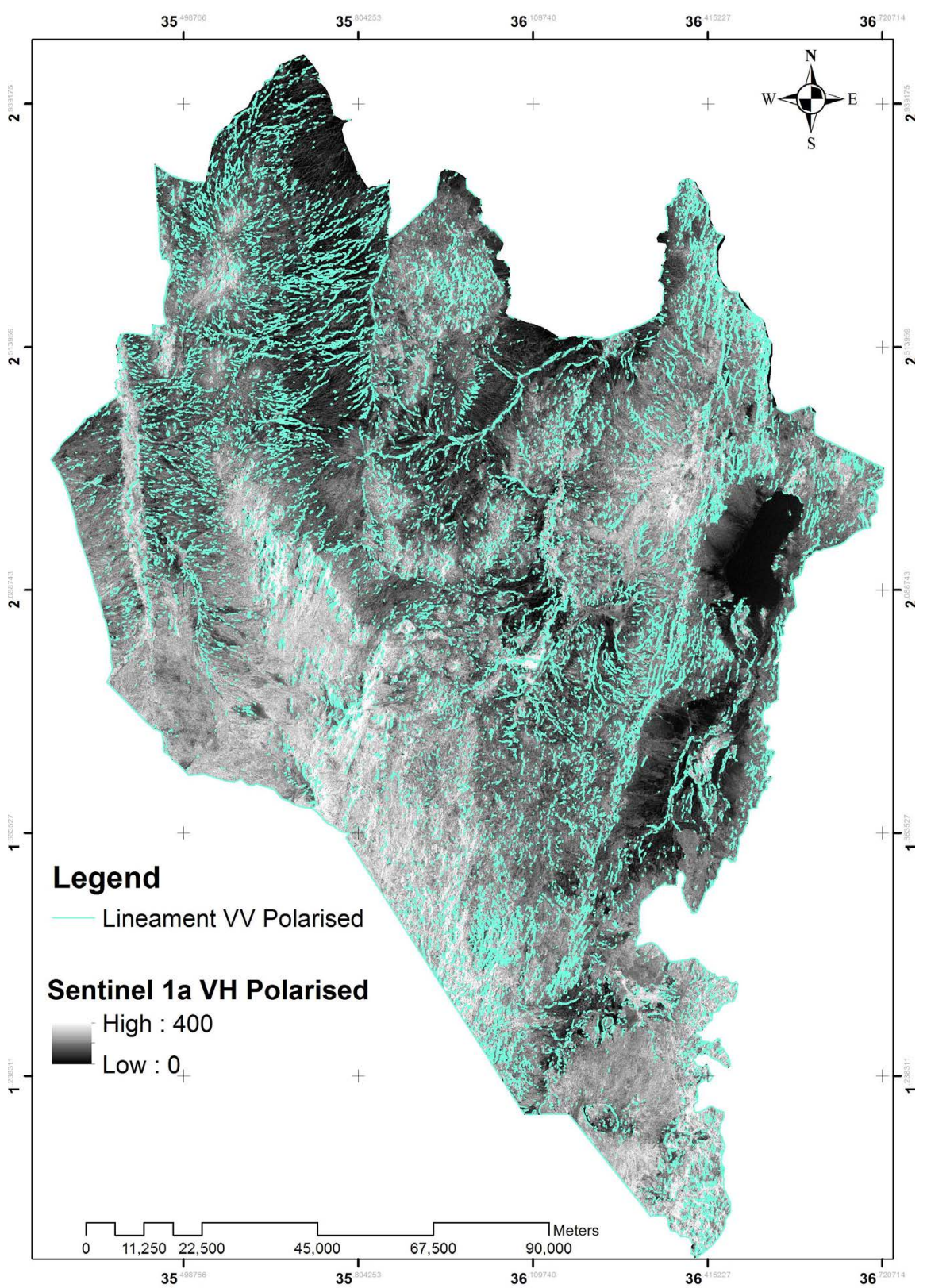

(b)

Figure 5. (a) Showing Sentinel 1a VH Polarized maps with area showing light toned and dark toned regions and (b) lineament VV polarized (green lines).

\section{Discussion}

The lineaments represent fractures and areas of weaknesses, thus centres of processes of weathering and lines of drainage which in weather-beaten environment habitually develop along pathways made possible by earlier weathering. The wider lineament images are a consequence of presence and the passage of water along the fractures every so often causes the vertical and lateral increase in weathering, henceforth the zone of influence expands with the presence of groundwater in the deeply weathered fracture zones. 


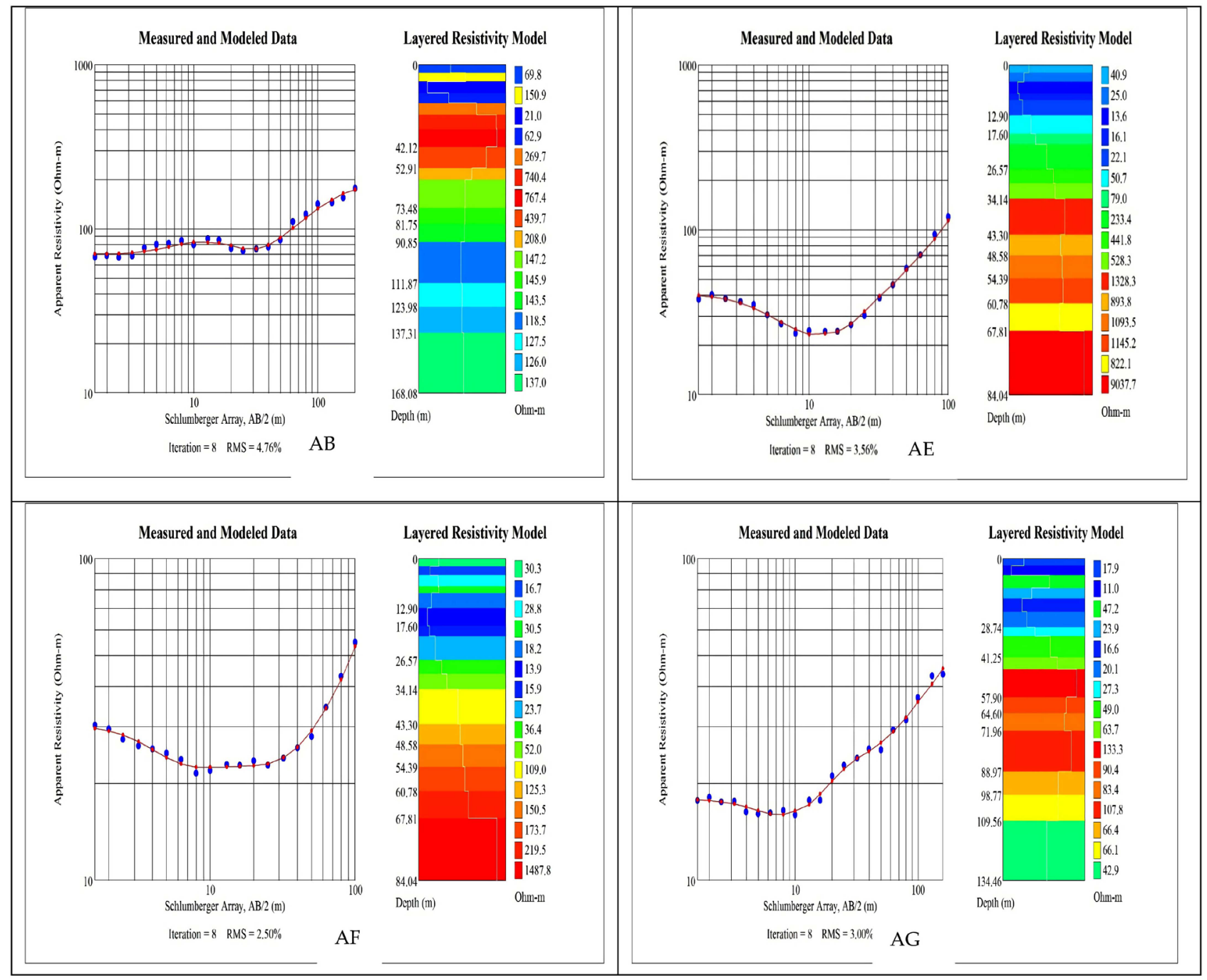

Figure 6. The analyzed VES points in the clockwise direction for (AB, AE, AG, and AF) of regions of low density present shallow depth groundwater potential in the range of $50 \mathrm{~m}$ to $100 \mathrm{~m}$.

The VES curve for point AA is a type KK which means that there are two combined K-type graphs with apparent resistivities $\rho_{1}<\rho_{2}>\rho_{3}<\rho_{4}$. This presents a four-layer model in which the information indicates geoeletrical layers of decreasing values that indicate more potential for groundwater potential as one goes deeper. The VES curve for point $\mathrm{AC}$ is a type $\mathrm{KH}$ graph with apparent resistivities $\rho_{1}<\rho_{2}>\rho_{3}>\rho_{4}$ which is also indicative of a four-layer model. It portends two aquifers where there is a shallower aquifer at about 10 metres deep which is associated with the sediments deposited in the area and a deeper one at about 40 to 80 metres associated with a concealed fault system in the area. The VES at point $\mathrm{AD}$ represents a type KK curve which means that there are two combined K-type graphs with apparent resistivities $\rho_{1}<\rho_{2}>\rho_{3}<\rho_{4}$. This presents only one deep aquifer at about 55 to 85 metres deep which is associated with the faulting in the area. The curve represented by the layered resistivity model for point AH is a type Q curve which is a three-layer model with apparent 


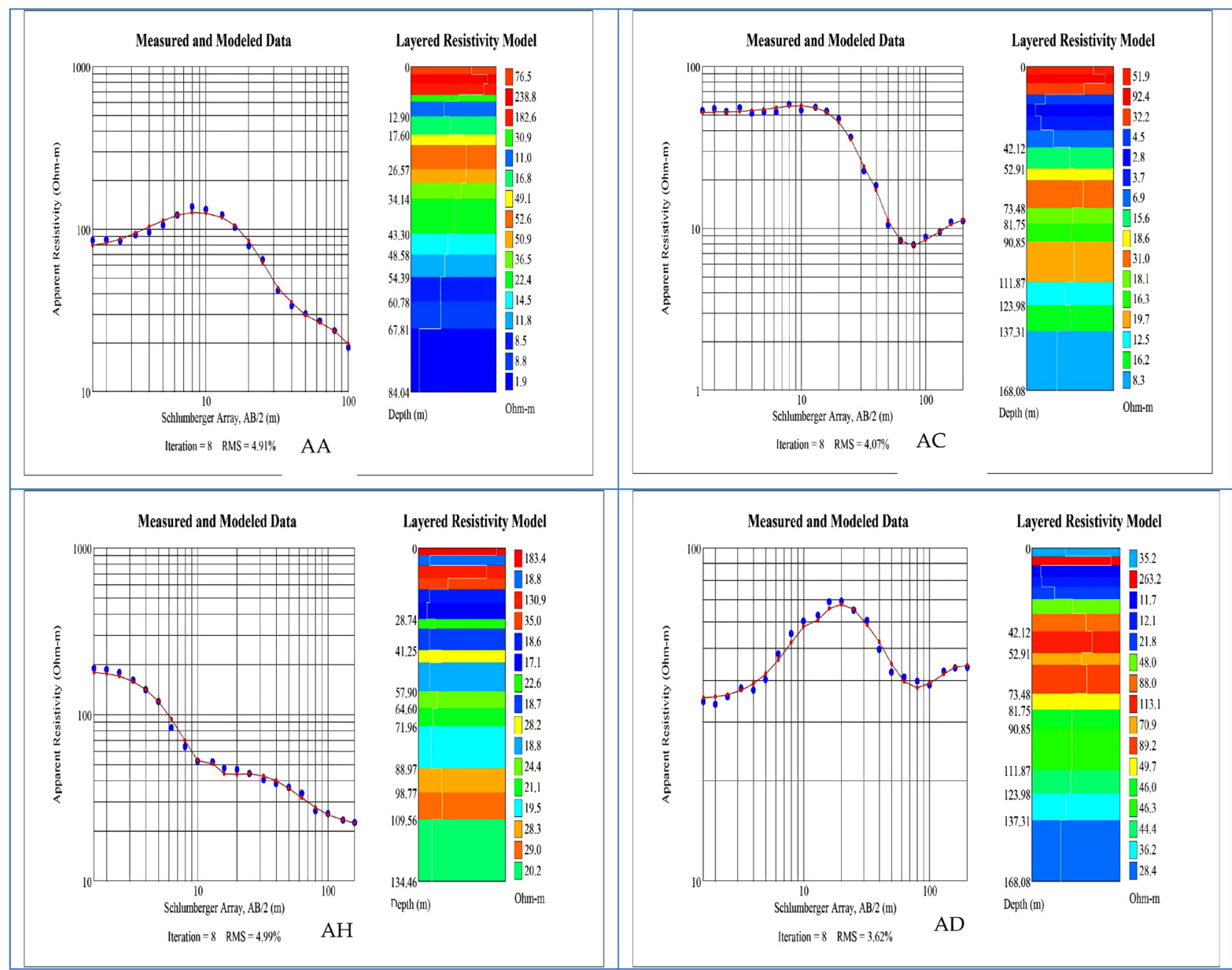

Figure 7. The analyzed VES profiles in the clockwise direction (AA, AC, AD and AH) showing groundwater potential at greater depths of beyond 150 metres in regions of high lineament density.

resistivities $\rho_{1}>\rho_{2}>\rho_{3}$. This is a showing of a continuous regime that indicates a non-concealed fault zone in the area and water is probable in all the depths up to about 140 metres deep as per the survey. These four points were picked for survey at areas which according to remote sensing analysis signified the points of high-intensity lineament and interpreted to mean regions affected by faulting and indeed as per the VES survey there is indication of low apparent resistivity zones, which are weak lithological zones presumed to contain water.

The layered resistivity model for point $\mathrm{AB}$ represents a type $\mathrm{A}$ curve which is a three-layer model with the apparent resistivities $\rho_{1}<\rho_{2}<\rho_{3}$. This shows an increasing resistivity with depth and that signifies a lithological setting which obeys the Law of Superposition where in its interpretation given the way of overlaying of geology the outcome is reduced porosity and permeability and therefore reduced electrical conductivity in the rocks with depth. This curve affords an interstitial aquifer about 20 metres deep which might be a boundary between two geological formations overlaying one another. These zones at times de- 
pending on the degree of weathering on the first laid layer before the episode of covering it with the top layer might present very good aquifers or otherwise poor aquifers. The curve for layered resistivity model for point $\mathrm{AE}$ is a type $\mathrm{H}$ curve which is unique in that the upward trajectory presents turn at an angle of 450. This is also a three-layer model with apparent resistivities $\rho_{1}\left\langle\rho_{2}\right\rangle \rho_{3}$. This presents a shallow aquifer up to 15 metres associated with sediments but otherwise the deeper regions are not viable. The presented resistivity also shows a continuous lithology obeying law of superposition. The curve type for layered resistivity model for point $\mathrm{AF}$ is type $\mathrm{HH}$, with apparent resistivities $\rho_{1}>\rho_{2}<\rho_{3}$, $\rho_{1}<\rho_{2}<\rho_{3}$, representing a three-layer model. This indicates an environment of thick sedimentation of about 40 metres deep overlying the basement. Depending on the lithological composition of the sediments may present a very good aquifer but otherwise a moderate to poor shallow aquifer. The layered resistivity model for point AG shows a type A curve with apparent resistivities $\rho_{1}<\rho_{2}<\rho_{3}$. This suggests an existence of sediment thickness of about 7 metres which has a declining resistivity and later an increasing resistivity portending an occurrence of basement rocks.

The VES interpreted data shows varying groundwater prospect depending on the density of the lineaments, with low-density lineament regions showing shallow groundwater occurrence and high-density lineament regions showing deeper probable potential. The analyzed VES points in the clockwise direction for $(\mathrm{AB}, \mathrm{AE}, \mathrm{AG}$ and $\mathrm{AF})$ in Figure 5 which are in areas having low lineament density, presents relatively shallow depth groundwater potential in the range of $50 \mathrm{~m}$ to $100 \mathrm{~m}$. The groundwater availability in these points is related to lithological formations where with increasing depth it portents occurrence of basement rock which naturally is considered of low groundwater potential. These points present increasing resistivity with increasing depth. The analysis of VES profiles in the clockwise direction (AA, AC, $\mathrm{AD}$ and $\mathrm{AH}$ ) in Figure 6 indicates better groundwater potential at greater depths of beyond 100 metres, a view supported by the reason that these points occur in fault-zones.

Remote sensing data is epitome for finding an overall overview of the morphological characteristics of a large research area at the commencement of the exploratory process, thus defining a smaller area as priority targets for more localize follow-up studies. This has effectively been applied to map lineaments in Turkana South Sub-County resulting in targeted points which have been confirmed through VES to be of potential for groundwater exploitation. Electrical resistivity through VES mode of deployment was handy in determining the resistivity of the geological media for the purpose of determining groundwater prospective in fractured unconfined aquifers in the predetermined points through remote sensing.

\section{Conclusion}

The remote sensing method has been successfully used to map regions of high 
and low-density lineaments in the study area. The regions of high-density lineaments were interpreted to refer to areas affected by faulting and deep weathering. In consideration of the interpretation of remote sensing data, the researcher concludes that the area is affected by different fault elements trending NE-SW, N-S and minor in the E-W reflecting the orientation of different lithologies and as an indication of past tectonic activities. Further use of vertical electrical sounding resistivity data resulted in the conclusion that the occurrence of groundwater in the study area is considered to exist either in zones of weaknesses necessitated by faulting and subsequent deep weathering, or in the interstitial openings in the beddings.

Thus it is evident that with integration of remote sensing and VES data, there is a better understanding of groundwater availability of the area. Although with the studies of using an integration of various method of survey is commended, still holding is the fact that groundwater potential of an area involves establishing its quantity and quality. Thus this is achieved by undertaking drilling and well test pumping which helps determine the yield and the subsequent quality analysis of the water to establish its portability.

\section{Acknowledgements}

Special thanks go to Water Resources Authority, Kenya, for provision of requested data and the technicians who were crucial in field data collection. Equally we acknowledge the support of Ministry of Petroleum and Mining, Kenya from whom geological maps were obtained, which were useful in production the final geological map of the area. Finally, we are grateful to the technicians; Chris and Fred who were instrumental in fieldworks.

\section{Conflicts of Interest}

The authors declare no conflicts of interest regarding the publication of this paper.

\section{References}

Anbazhagan, G., \& Manivel, M. (2010). Targeting Groundwater Potential Zones in Hard Rock Terrain Using Remote Sensing and GIS.

Champion, A. M. (1935). Teleki's Volcano and the Lava Fields at the Southern End of Lake Rudolf. The Geographical Journal, 85, 323-336. https://doi.org/10.2307/1785591

Dodson, R. G. (1963). Geology of the Area South of Lodwar. Geological Survey of Kenya.

Fairburn W. A., \& Matheson F. J. (1970). Geology of the Loiya-Lorugumu Area. Geological Survey of Kenya.

Government of Kenya (2013). Turkana County Integrated Development Plan 2013-2017, Report. https://turkana.go.ke/wp-content/uploads/2016/10/Turkana-CIDP-Final-1.pdf

Gwynne, M. D. (1969). The South Turkana Expedition Scientific Papers I. Preliminary Report on the 1968 Season. The Geographical Journal, 135, 331-342. https://doi.org/10.2307/1797322

Jawad, T. A., \& Yahya, Y. A. (2013). Application of GIS and Remote Sensing to Ground- 
water Exploration in Al-Wala Basin in Jordan. Journal of Water Resource and Protection, 5, 962-971. http://www.scirp.org/journal/jwarp https://doi.org/10.4236/jwarp.2013.510099

Kamal, K., \& Hamid, R. N. (2011). Groundwater Exploration Using Remote Sensing and Geographic Information Systems in a Semi-Arid Area (Southwest of Urmieh, Northwest of Iran). Arabian Journal of Geosciences, 6, 1229-1240.

https://doi.org/10.1007/s12517-011-0414-4

Maina, M. M., \& Tudunwada, I. Y. (2017). Lineament Mapping for Groundwater Exploration in Kano State, Nigeria. International Journal of Advances in Agricultural \& Environmental Engineering, 4, 226-229.

Mason, P., \& Gibson, A. B. (1957). Geology of the Kalossia-Tiati Area. Geological Survey of Kenya.

McCall, G. J. H. (1964). Geology of the Sekerr Area. Geological Survey of Kenya.

Mogaji, K. A., Aboyeji, O. S., \& Omosuyi, G. O. (2011). Mapping of Lineaments for Groundwater Targeting in the Basement Complex Region of Ondo State, Nigeria, Using Remote Sensing and Geographic Information System (GIS) Techniques. International Journal of Water Resources and Environmental Engineering, 3, 150-160. http://www.academicjournals.org/ijwree

Opiyo, F. E. O. (2014). Climate Variability and Change on Vulnerability and Adaptation among Turkana Pastoralists in North-Western Kenya. Ph.D. Thesis, Nairobi: Faculty of Agriculture, University of Nairobi.

Rhett, H. (2001). An Introduction to Electrical Resistivity in Geophysics. American Journal of Physics, 69, 943-952. http://ojps.aip.org/ajp/ https://doi.org/10.1119/1.1378013

Saint-Jean, R., \& Singhroy, V. (2000). Hydrogeological Mapping in the Semi-Arid Environment of Eastern Jordan Using Airborne Multipolarized Radar Images. https://www.researchgate.net/publication/277244840 https://doi.org/10.4095/219743

Shefali, A. (2013). Principles of Remote Sensing. Satellite Remote Sensing and GIS Applications in Agricultural Meteorology (pp. 23-38).

Sultan, R. (1970). The South Turkana Expedition: Scientific Papers III. A Geological Reconnaissance of South Turkana. The Geographical Journal, 136, 61-73.

http://www.jstor.org/stable/1795682

https://doi.org/10.2307/1795682

Surajit, M. (2014). Analysis of Groundwater Potential Zones Using Electrical Resistivity, $R S$ and GIS Techniques in a Typical Mine Area of Odisha. A Dissertation Submitted in Partial Fulfillment of the Requirements for the Award of the Degree of Master of Technology in Civil Engineering with Specialization in (Water Resources Engineering). https://www.researchgate.net/publication/321331597/download

Turkana County Government Report (2015). Natural Resource Mapping and Context Analysis.

https://turkana.go.ke/wp-content/uploads/2016/10/Final-Report-Natural-Resource-Ma pping-Context-Analysis-.pdf

Zakaria, A., Abderrazak, E. H., Amine, J., Rachid, L., Lhou, M., Mohamed, A. et al. (2017). Comparison of Landsat-8, ASTER and Sentinel 1 Satellite Remote Sensing Data in Automatic Lineaments Extraction: A Case Study of Sidi Flah-Bouskour Inlier, Moroccan Anti Atlas. Advances in Space Research, 60, 2355-2367.

https://www.sciencedirect.com/science/article/pii/S0273117717306397

https://doi.org/10.1016/j.asr.2017.09.006 